\title{
SOME GENERAL QUADRATIC NUMERICAL RADIUS INEQUALITIES FOR THE OFF-DIAGONAL PARTS OF $2 \times 2$ BLOCK OPERATOR MATRICES
}

\author{
Rongfang Li, Deyu Wu* and Alatancang Chen
}

\begin{abstract}
In this paper, the elementary properties for the quadratic numerical radius are introduced. Furthermore, some general quadratic numerical radius inequalities for the off-diagonal parts of $2 \times 2$ block operator matrices are studied. These inequalities are based on the generalized mixed Schwarz inequality, Young inequality and Jensen inequality.
\end{abstract}

Mathematics subject classification (2020): 47A12.

Keywords and phrases: Bounded block operator matrix, quadratic numerical range, qadratic numerical radius, mixed Schwarz inequality, Young inequality, Jensen inequality.

\section{REFERENCES}

[1] M. G. Aghideh, M. S. Moslehian and J. Rooin, Sharp inequalities for the numdrical radii of block operator matrices, Anal. Math. 45, no. 4 (2019), 687-703.

[2] H. Albadawi AND K. SheBRAWI, Inequalities for powers of the numerical radii of Hilbert space operators, Int. J. Math. Anal. 2, no. 9-12 (2008), 527-532.

[3] Y. Al-Manasrah and F. Kittaneh, A generalization of two refined Young inequalities, Positivity, 19, no. 4 (2015), 757-768.

[4] M. BAKHERAD AND K. SHEBRAWI, Upper bounds for numerical radius inequalities involving offdiagonal operator matrices, Ann. Funct. Anal. 9, no. 3 (2018), 297-309.

[5] F. A. BANI-AHMAD AND W. BANI-DomI, New norm equalities and inequalities for operator matrices, Journal of Inequalities and Applications, 175, no. 1 (2016), 1-9.

[6] S. S. DRAGOMIR, A potpourri of Schwarz related inequalities in inner product spaces ( П), Journal of Inequalities in Pure and Applied Mathematics, 7, no. 1 (2005), 1-11.

[7] S. S. Dragomir, Inequalities for the Numerical Radius of Linear Operators in Hilbert Spaces, Springer, Melbourne, 2013.

[8] M. El-HAdDAD AND F. KITTANEH, Numerical radius inequalities for Hilbert space operators П, Studia Mathematica, 182, no. 2 (2007), 133-140.

[9] M. ERFANIAN AND H. R. MoRADI, New estimates for the numerical radius of Hilbert space operators, Linear and Multilinear Algebra, (2020), https://doi.org/10.1080/03081087.2020.1810200.

[10] K. E. Gustafson AND D. K. M. RaO, Numerical range, Springer-Verlag, New York, 1997.

[11] M. HAJMOHAMADI, R. LASHKARIPOUR AND M. BAKHERAD, Some generalizations of numerical radius on off-diagonal part of $2 \times 2$ operator matrices, Journal of Mathematical Inequalities, 12, no. 2 (2018), 447-457.

[12] G. H. Hardy, J. E. Littlewood AND G.Pólya, Inequalities, 2nd edn, Cambridge University Press, Cambridge, 1998.

[13] O. Hirzallah, F. Kittaneh and K. Shebrawi, Numerical radius inequalities for certain $2 \times 2$ operator matrices, Integr Equ Oper Theory, 71, no. 1 (2011), 129-147.

[14] J. A. R. Holbrook, Multiplicative properties of the numerical radius in operator theory, J. Reine Angew. Math. 237 (1969), 166-174. 
[15] F. Kittaneh, Notes on some inequalities for Hilbert space operators, Publ. Res. Inst. Math. 24, no. 2 (1998), 283-293.

[16] H. Langer, A. Markus, V. Matsaev and C. Tretter, A new concept for block operator matrices: the quadratic numerical range, Linear Algebra Appl., 330, no. 1-3 (2001), 89-112.

[17] H. LANGER AND C. TRETTER, Spectral decomposition of some nonselfadjoint block operators matrices, J. Operator Theory, 39, no. 2 (1998), 339-359.

[18] R. Li, D. Wu AND A. Chen, On the geometry of the quadratic numerical range for $2 \times 2$ block operator matrices, Linear and Multilinear Algebra, (2020), https://doi.org/10.1080/03081087.2020.1759501.

[19] M. S. MosLehian AND M. SATTARI, Inequalities for operator space numerical radius of $2 \times 2$ block matrices, J. Math. Phys., 57, no. 1 (2016), 015201.

[20] A. RADL, Perron-Frobenius type results for the block numerical range, Proc. Appl. Math. Mech. 14, no. 1 (2014), 1001-1002.

[21] M. Sattari, M. S. Moslehian And T. YAmazaki, Some generalized numerical radius inequalities for Hilbert space operaors, Linear Algebra and its Applications, 470 (2015), 216-227.

[22] K. Shebrawi AND H. Albadawi, Numerical radius and operator norm inequalities, Journal of Inequalities and Applications, 9, no. 11 (2009), 1-11.

[23] C. TReTter, Spectral Theory of Block Operator Matrices and Applications, Imperial College Press, London, 2008.

[24] C. TRETTER, The quadratic numerical range of an analytic operator function, Complex Anal. Oper. Theory. 4, no. 2 (2010), 449-469. 